\title{
Construction of Plunge Column by using Top Down Construction Method
}

\author{
${ }^{* 1}$ Nikhil S. Agrawal, ${ }^{2}$ Varsha Harne, ${ }^{3}$ Jyoti Chouhan, ${ }^{4}$ Laxmi Gangwani \\ ${ }^{1,2,3,4}$ Department of Civil Engineering, Shri Ramdeobaba College of Engineering and Management, Nagpur- 440012 , \\ Maharashtra, India \\ Email: agrawalns9@rknec.edu,harnevr@rknec.edu,chouhanjb3@rknec.edu,gangwanilr@rknec.edu
}

\author{
Received: 06th November 2019, Accepted: 10th February 2020, Published: 29th February 2020
}

\begin{abstract}
In an age where every square millimetre has the potential to earn money, it is essential to maximize the floor space in today's property developments and the extend goes to the record-breaking basements too. While this may seem like another difficult demand for those involved in such projects, but our believe is that bar can be raised traditional, buildings with underground basements are built by Bottom-up method where sub-structure and super- structure floors are constructed in a sequence from the bottom of the sub structure to the top of the super-structure. Though this traditional method is simple in both design and construction, it is not feasible for the huge projects with limited construction time. So to counter this we have come up with top down construction as in the deepest underground station in New Delhi, India at Hauzkhas. Top-down construction method as the name implies, is a construction method, which builds the permanent structure members of the basement along with the excavation from the top to the bottom. This construction method, which provides us with saving of the overall construction time, it is showing increasing adoption for major projects where time factor is of primary importance. But this method wouldn't be possible without the help of the plunge columns that acts as a vertebra to this technique, which helps in holding all the loads that is laid during the process. A plunge column is a structural steel or concrete section embedded in a freshly poured concrete pile, eliminating the need for base plates and holding-down bolts. Plunge columns can be installed into rotary bored piles to allow for a 'top-down' construction sequence; 'launching' the structures much before the basement is excavated. By adopting this method of construction the client can gain advantage of a reduced construction programme.
\end{abstract}

\section{Keywords \\ Plunge Columns, Top-down Construction, Bottom up Constructions}

\section{Introduction}

In conventional building the basement construction are possible with the help of two techniques bottom up and top down construction method. Bottom up as the name suggest is the process where the sub structure and the super structure are constructed simultaneously from the lowest level of basement to the top of superstructure.[7] Although this process is simple in design and construction, it is not feasible for gigantic projects with limited construction time and space. So, to overcome it we came up with the other process the Top Down construction method which builds the permanent structure members of the basement along with the excavation from top to bottom [2] and it has been mainly used for construction of tall buildings with deep basement and underground structures like metro stations. Many researchers explain about this top down construction method for e.g. Chang- Yu Ou (Sept.1998) [1] \& also by Jian Jia (2012) [3]. This paper presents the technique of top down construction with the help of the load bearing elements known as the plunge column. The plunge columns are positioned into rotary bored piles to smoothen the 'Top-Down' construction sequence, [8] so that the structure is launched before the excavation of the basement. These columns are the key to top down construction, as they help in the parallel construction of superstructure and the basement excavation, thereby significantly improving the project programme. Jing-Ying wong (2019)[6] investigate the effectiveness of top down construction method in Malaysia in which the building sequence starts with the construction of retaining wall and the underground load bearing elements which carry the future superstructure. This research aims to evaluate the strength and weakness of TDC approach compared to the conventional bottom-up method in Malaysia through different aspects and improvements are proposed at the end of the study. 


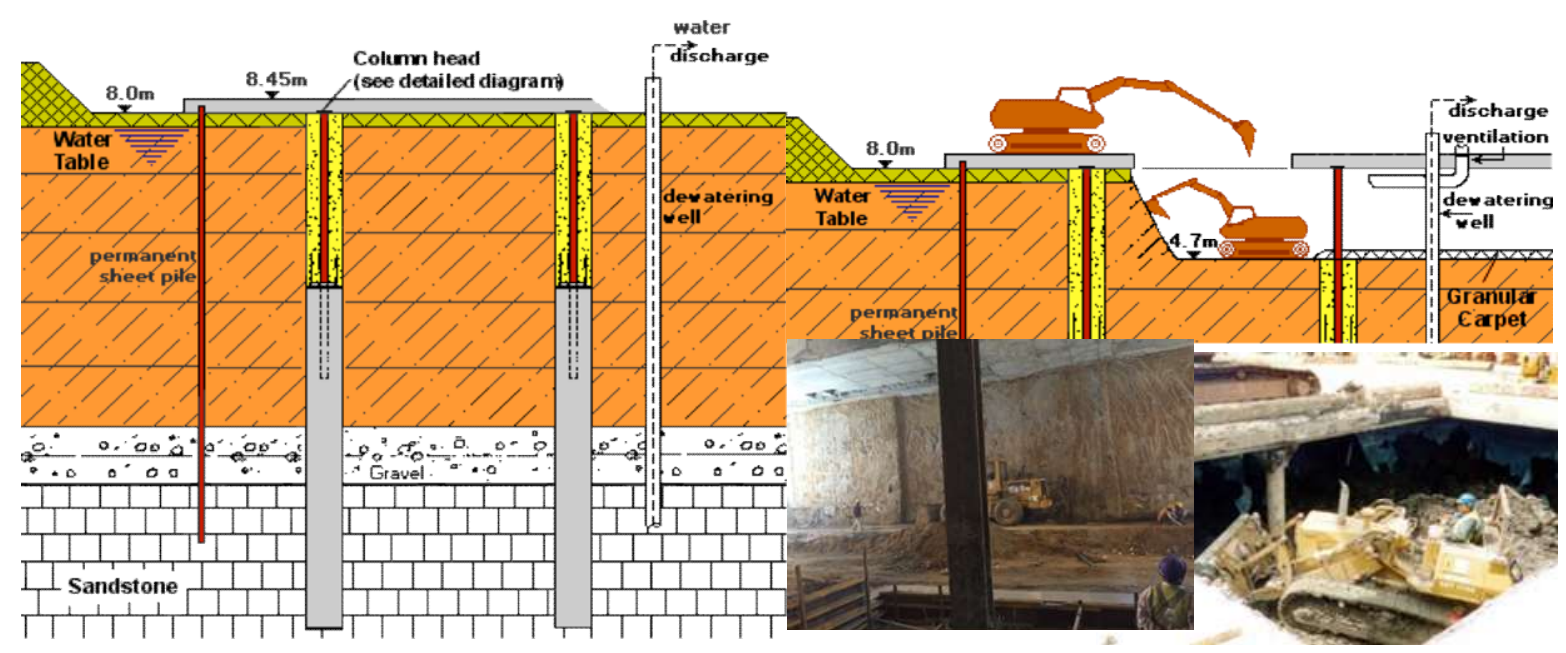

Fig.1: Location of Plunge Column in Top Down Construction

Design principles involved in bottom up construction, top down construction and plunge column. Bottom up method requires a very large working space as we have to first excavate the area and then begin with the actual construction, alternate to bottom up method is top down construction method that does not requires a very large space and it enables simultaneous construction of high rise superstructure and sub basement [4] which means an accelerated construction process and cost saving but the major advantage of this process is that it reduces the soil movement [5] and even prevents the settling of the structure as shown in fig. 1

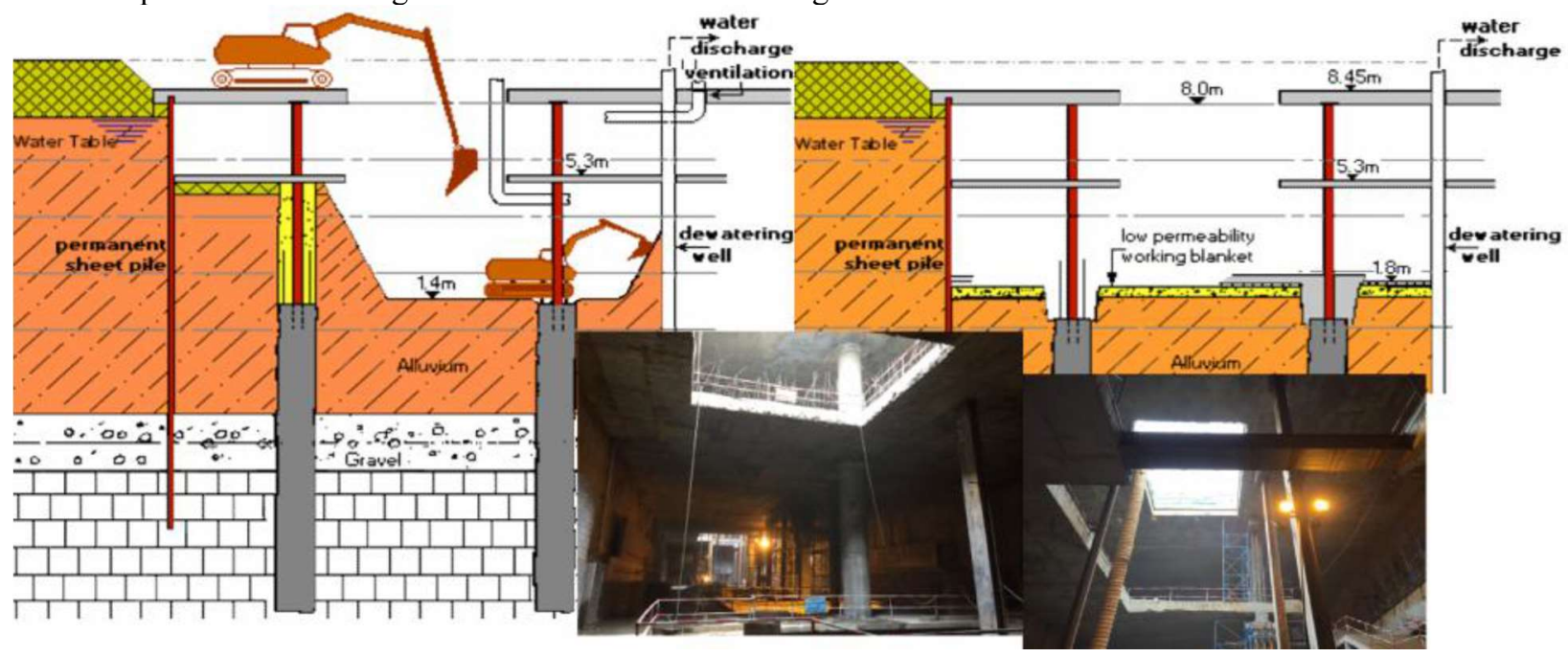

Fig. 2: Process of Top down Construction with Plunge Column

The top down construction method starts with the construction of the retaining wall called as the D wall or the diaphragm wall which helps in holding the soil from sides then comes piling, after that the steel columns or props are placed where the piles are constructed. One of the researcher explain about this diaphragm wall or D wall for e.g. Chang-Yu Ou (Sept.1998) [1] as per literature performance of diaphragm wall with soil and time also studied also explain about moments of diaphragm wall and soil. First step starts with the excavation and the casting of the floor slab of the basement level and simultaneously begin to construct the superstructure, step two is to excavate and cast the floor slab for the second level basement as shown in fig 2,then the same procedure is repeated till the required depth is reached then finally comes the construction of the foundation slab and ground beams after completing the basement [10] the construction of the superstructure goes on till it gets completed; but all this is possible with the help of plunge column that are the basics of the top down method, the columns can be either permanent or temporary depending on the usage and can be removed and reused. 


\section{Construction Methodology of Plunge Column:}

The first step is the survey of the ground and the conditions of the soil, then comes the piling of the soil or the rock with the help of rotary bored pile and it is excavated to the necessary depth as. After that polymer slurry is used, this forms a filter cake on walls to support the earth pressure. This new generation slurry has many advantages over the old generation bentonite slurry as it is infinitely reusable and it is required in a very small amount, and even the cost of disposal is very low as compared to the bentonite slurry. The reinforcement cage is fitted and then the voids are filled with concrete discontinuing the required distance below the ground level.[6] While the concrete is still wet the hydraulic plunging frame are used \& it is installed within the provisional casing and then the plunge column is installed.[7] The concrete is then left to set in the pile as shown in fig 3.

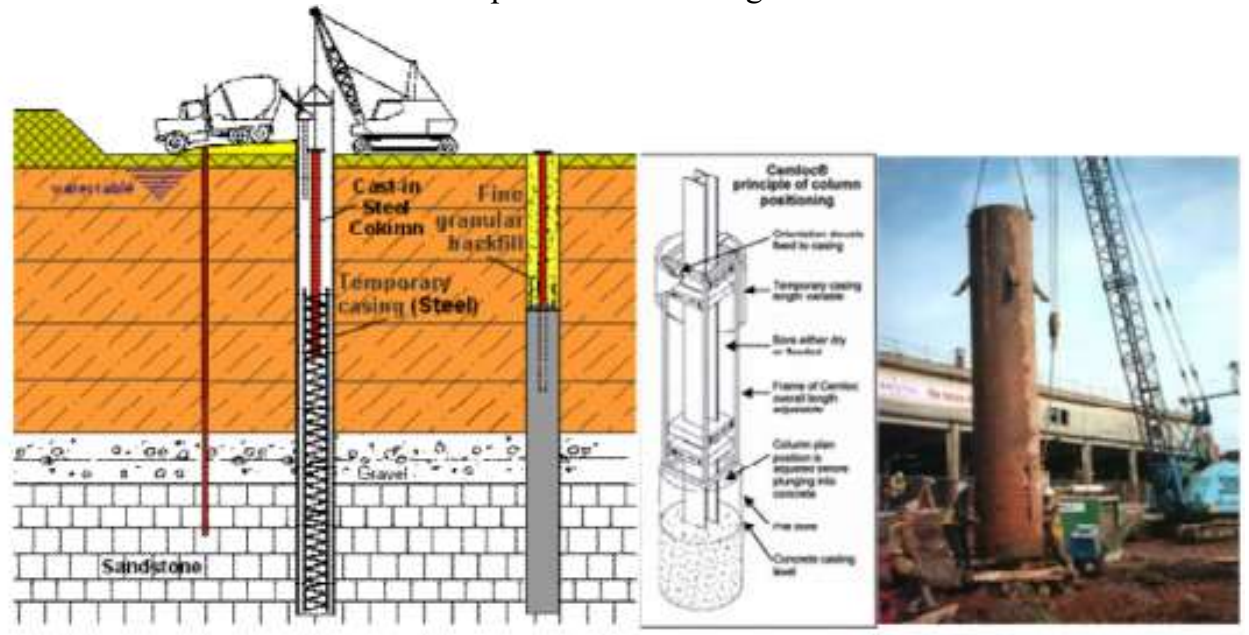

Fig. 3: Placing \& Concreting of Plunge Column

There are two ways to install these columns, which are based on 3 important factors namely

1) Installation depth

2) Size of column

3) Size of bored pile

Methods of installation of the column

1. Post-concreting installation-column is installed instantly after completion of bored pile concreting process. [9] Firms have developed jigs to enable the steel plunge column to be placed very accurately both in verticality and position within the unlined box supported by bentonite slurry.

2. Pre-concerting installation method-in this method the column is installed instantly after the accomplishment of drilling and reinforcement lowering prior to concreting process. Sometimes the column is supporting to the last unit of reinforcement and installed.

\section{Result and Discussion}

1. Plunge column has number of advantages in foundation construction in the process like the top down method, which has now picked up the speed in India

2. This process is already been used in construction of metro stations in New Delhi, Kolkata etc.

3. There can be considerable reduction in capital cost by using top down method which in-turn saves the total construction time, generates financial returns \& helps in holding cost reductions, it also helps in keeping down the dust levels to a minimum.

4. It also has a very wide applicability in buildings with basements these columns help in minimizing the programme time.

\section{Conclusion}

1. With the help of these columns the volume of concrete used is reduced, thereby reducing of the cost and carbon output savings.

2. Traffic disruption to surrounding roads are kept to minimum as the there is no need of excavation on large scale like the bottom up technique it is Ideal for excavation projects where tieback installation is not affordable and where movement of soil must be reduced. 
3. Structural steel acceptances are achieved, the permanent liners are not required and workforce is not required to descend to trim back the pile head and there is no need for base plates or pile cap.

4. There are some limitations in using plunge columns as they require heavy reinforcement, the construction of the columns can be uneconomical sometimes as the wastage of steel is done in large amount as some columns are temporary and they are removed after the use simultaneously there is large wastage of concrete and this process requires skilled labors to demolish them.

5. This method cannot be used for small projects and housing schemes and generally requires big projects, as it is not feasible for small projects.

\section{References}

[1] Chang-yu ou; member, ASCE, jui-thng liao/ and horn-da lin,3 member, ASCE; Performance of diaphragm wall constructed using Top-down method

[2] El Arif Fatima Zahra, Hinti Said Application of the approaches Top-down and Bottom-up for the construction of a Risk Mapping of an insurance company" IOSR Journal of Business and Management (IOSR-JBM) e-ISSN: 2278487X, p-ISSN: 2319-7668. Volume 16, Issue 3. Ver.I (Mar. 2014), PP 60-67

[3] Jian $\mathrm{Jia}^{1}$; xiaolin $\mathrm{Xie}^{2}$; jiequn Zhai ${ }^{3}$; Yu Zhang ${ }^{4}$; Ke Yang ${ }^{5}$; and Xiao Hang Guo; Research and Design on TopDown Method for Large Scale Podium Basement Excavation of Shanghai Tower

[4] J.Y.H. Lui, and P.K.F. Yau, The performance of deep basement for the dragon centre, Proc. Of Seminar on Instrumentation in Geotechnical Engineering, Hong Kong Institution of Engineers, 1995, 813 -201.

[5] James sze "Deep foundation for high rise buildings in hongkong" International Journal of high rise buildings volume 4 No.4

[6] Jing-Ying Wong, Chun-Chieh Yip, Kevin Luwemba Mugumya, Bing-Hong Tan, Mohammed Parvez Anwar "Effectiveness of Top-Down Construction Method in Malaysia" ISSN: 2278-3075, Volume-8, Issue-6S4, April 2019

[7] M. Puller, Deep excavations - a practical manual (2ndedition, Thomas Telford Ltd., London, 2003)

[8] M.S. Fletcher, the 'Down' of Top-down, Civil Engnrs, 58, 1988, 58-61

[9] S.S. Basarkar, Manish Kumar B.G., Mohapatro P.R., Mutgi "Emerging Trend in Deep Basement Construction Top Down Technique" IOSR Journal of Mechanical and Civil Engineering (IOSR-JMCE) ISSN: 2278-1684, PP: 01-11

[10] Stephen TM Young "Deep Basement Construction through an Existing Basement at the Central Business District of Hong Kong "International conference on case Histories in Geotechnical Engineering. 